\title{
Destrucción del tendón bicipital en el codo por bursitis bicipitorradial reumatoide
}

\author{
G. Celester Barreiro $^{(1,2)}$, A. Prego Bestilleiro ${ }^{(1,2)}$, G. Monje Cruz $^{(1)}$, \\ R. Arriaza Loureda ${ }^{(1)}$, B. López Cantos $^{(3)}$ \\ (1) Unidad de Cirugía de la Mano del Instituto Médico ArRiaza y Asociados \\ (2) Unidad de Cirugía de la Mano del Hospital Modelo. A Coruña \\ (3) Servicio de Radiología del Hospital Santa Teresa. A Coruña
}

Correspondencia

Dr. Gabriel Celester Barreiro

Instituto Médico Arriaza y Asociados

C/ Enrique Mariñas s/n. Edif. Sport Centre

15004 A Coruña

e-mail: gcelester@mundo-r.com

La artritis reumatoide es una enfermedad inflamatoria sistémica crónica de origen desconocido que afecta preferentemente a las membranas sinoviales de las articulaciones, tendones y bursas, y tiene numerosas manifestaciones intra y extraarticulares. De estas últimas las más frecuentes son los nódulos reumatoides y las bursitis.

Describimos el caso de una paciente con una bursitis bicipital reumatoide de tan larga data y ausencia de síntomas que acabó con una lisis del tendón distal del biceps brachii.

Palabras clave: artritis reumatoide, bursitis reumatoide, bursitis bicipital, nódulo reumatoide, codo,
Rheumatoid arthritis is an inflammatory systemic chronic disease of unknown origin that it affects preferentially the synovial membranes of the joints, tendons and bursas, and has numerous manifestations intra-articular and extra-articular. Of these the most common are the rheumatoid nodules and the bursitis. We then describe the case of a patient with a bicipital rheumatoid calcific bursitis of so longstanding and absence of symptoms that finished with an destruction of the distal tendon of the biceps brachii.

Key words: rheumatoid arthritis, rheumatoid bursitis, bicipital bursitis, rheumatoid nodule, elbow.

\section{INTRODUCCIÓN}

T as tumoraciones de partes blandas en el miembro superior son lesiones muy frecuentes y casi siempre benignas.

El diagnóstico clínico preoperatorio en raras ocasiones es fiable - apenas en algunos tumores cutáneos y quistes sinoviales- por lo que la mayor parte de las veces el diagnóstico de presunción es intraoperatorio y la certeza sólo es posible mediante el estudio histológico.
Las pruebas de exploración, especialmente la ecografía y la RM - más precisas que la radiografía simple y la TC para este tipo de lesionesson de gran ayuda para su localización y medida, pero son bastante inespecíficas en cuanto al tipo histológico y variedad del tumor. De ahí que a menudo el cirujano se encuentre en los informes anatomopatológicos la sorpresa de tumores inesperados.

El concepto de tumoración como tumefacción, bulto o hinchazón de carácter patológi- 

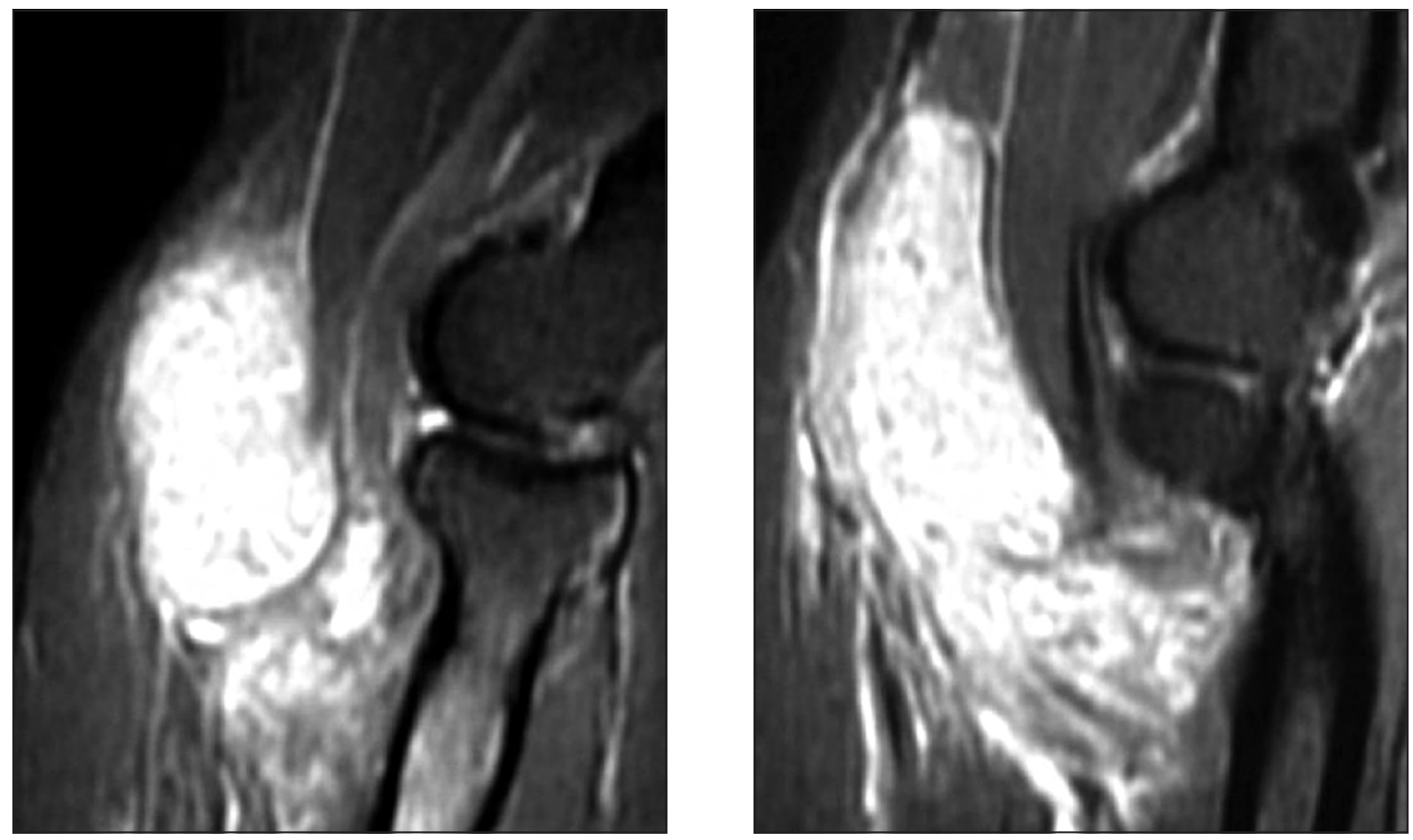

Figura 1: Imágenes de la RM mostrando el aspecto, localización y tamaño de la tumoración en el plano axial.

co, según la RAE, es demasiado inespecífico y confuso. Incluye a los verdaderos tumores y un cajón de sastre de lesiones difíciles de clasificar, reunidas a menudo con el epígrafe de lesiones seudotumorales.

Las bursitis y los nódulos reumatoides no son tumores en sentido estricto, sino procesos inflamatorios cutáneos o subcutáneos, y no se consideran lesiones seudotumorales aun cuando se comporten como éstas en cuanto pueden producir molestias por la compresión o la destrucción de los tejidos adyacentes.

Las bursitis pueden tener un origen mecánico (agudo por contusión, subagudo, o crónico por fricción), séptico, tumoral, metabólico en enfermedades por depósitos de cristales (gota y seudogota), y como manifestación de diversas enfermedades inflamatorias sistémicas como la artritis reumatoide (AR).

Dentro de las manifestaciones extraarticulares de la AR las más frecuentes son la existencia de nódulos reumatoides y la vasculitis reumatoide $^{1}$. Los nódulos subcutáneos palpables (entre 1 y $5 \mathrm{~cm}$ ) están presentes en el 20-30\% de los pacientes $^{1,2}$, pero algunos autores ${ }^{3}$ creen que los microscópicos se dan en el 100\% de los casos. Las bursitis reumatoides superficiales no son raras, siendo la más frecuente la olecraneana, casi siempre en combinación con nódulos subcutáneos en la cara posterior del codo adheridos al periostio del olécranon.

\section{CASO CLÍNICO}

Mujer de 56 años diagnosticada de artritis reumatoide (AR) que en la revisión de una prótesis de cadera, como algo irrelevante y añadido, consultó la presencia de una tumoración de partes blandas en el pliegue de flexión del codo derecho con más de 2 años de evolución, indolora, no rodadera, sobre la cual la piel se desplazaba con normalidad. La movilidad del codo estaba conservada. El colega que la vio anotó su impresión de sinovitis articular o lipoma extraarticular y pidió una RM.

Esta prueba (Figuras 1 y 2) mostró la existencia de una masa sólida, discretamente lobulada y bien delimitada en los tejidos blandos de la cara anterior del codo, de unos $10 \mathrm{~cm}$ de eje craneocaudal siguiendo el recorrido del tendón 

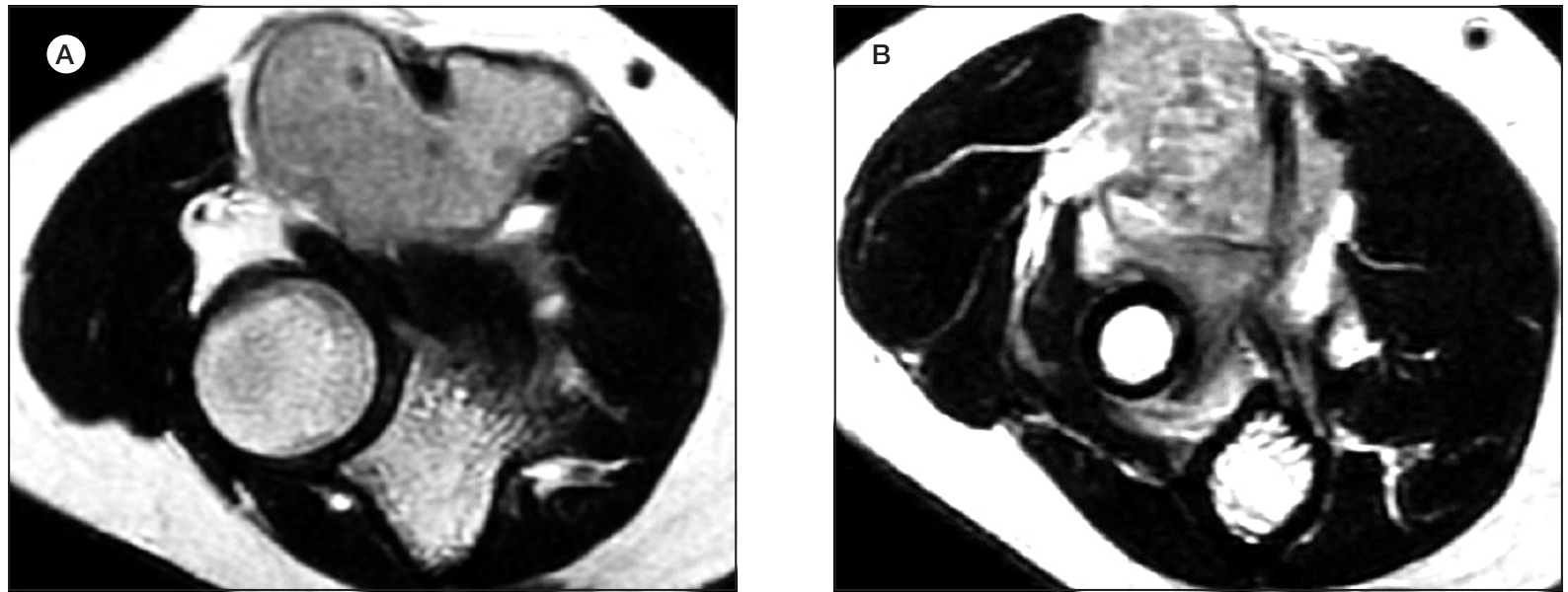

Figura 2: Imágenes de la RM en las que se aprecia el tamaño de la tumoración en el plano sagital y cómo rodea el cuello del radio.

distal del biceps brachii. El informe consideraba como primera posibilidad diagnóstica una masa de origen sinovial a valorar en el contexto de su enfermedad.

Bajo anestesia regional intravenosa e isquemia se realizó abordaje anterior del codo para biopsia. El aspecto macroscópico intraoperatorio era el de una tumoración lisa en su cara anterior (Figura 3A), bien delimitada de los tejidos ad-
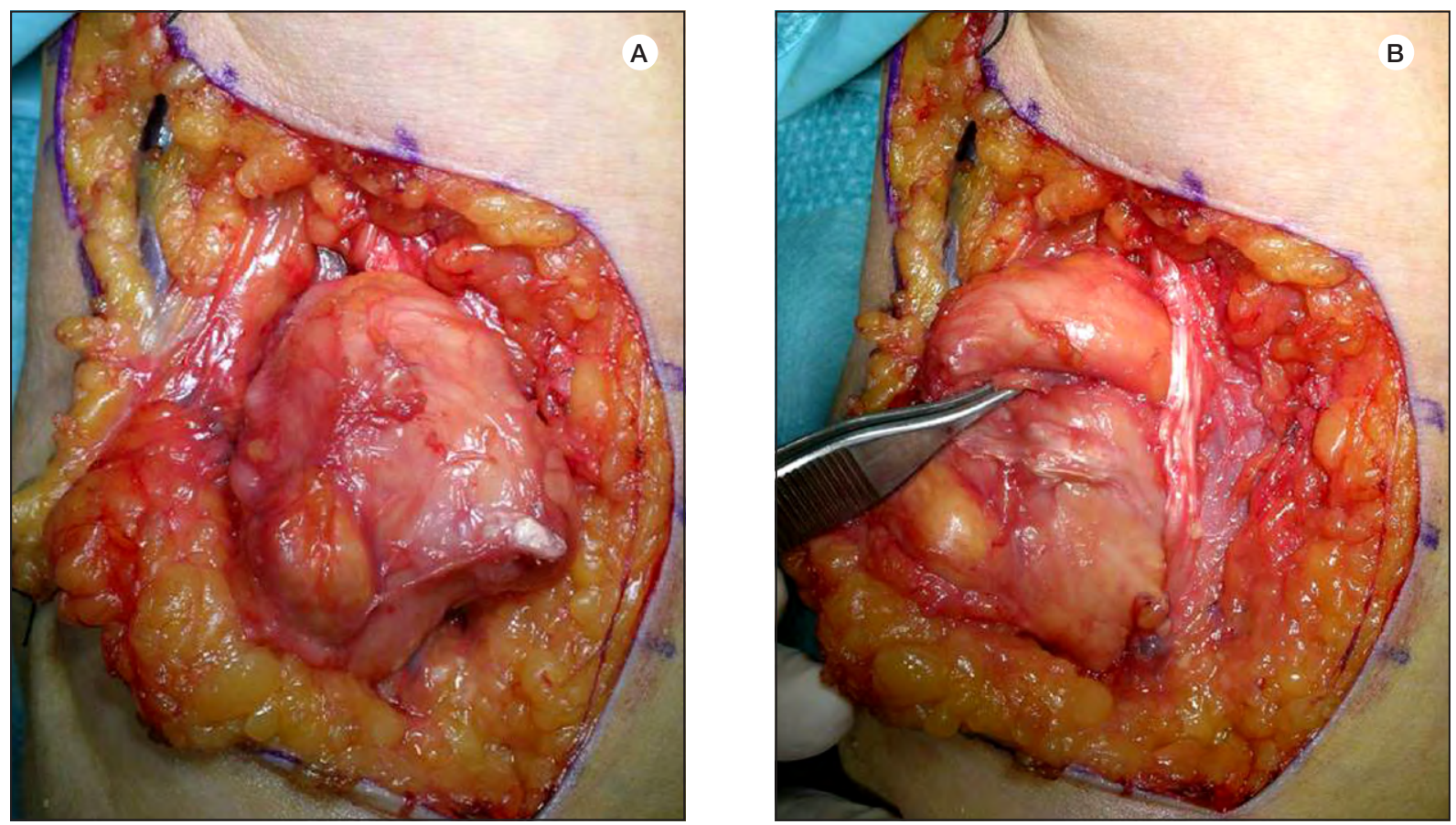

Figura 3: Caras anterior y posterior de la tumoración. La figura $3 B$ muestra el aspecto del tendón bicipital, reducido a una mera cintilla sin función. yacentes. Su cara posterior (Figura 3B), sobre la cápsula articular y encima de la arteria humeral y del nervio mediano, estaba en íntimo contacto con el tendón bicipital; el cual, sumamente adelgazado por la compresión, se hallaba convertido en una fina cintilla muy laxa, de aspecto poco o nada funcional. En su parte más profunda, la masa rodeaba al cuello del radio al que se encontraba fuertemente adherida. 


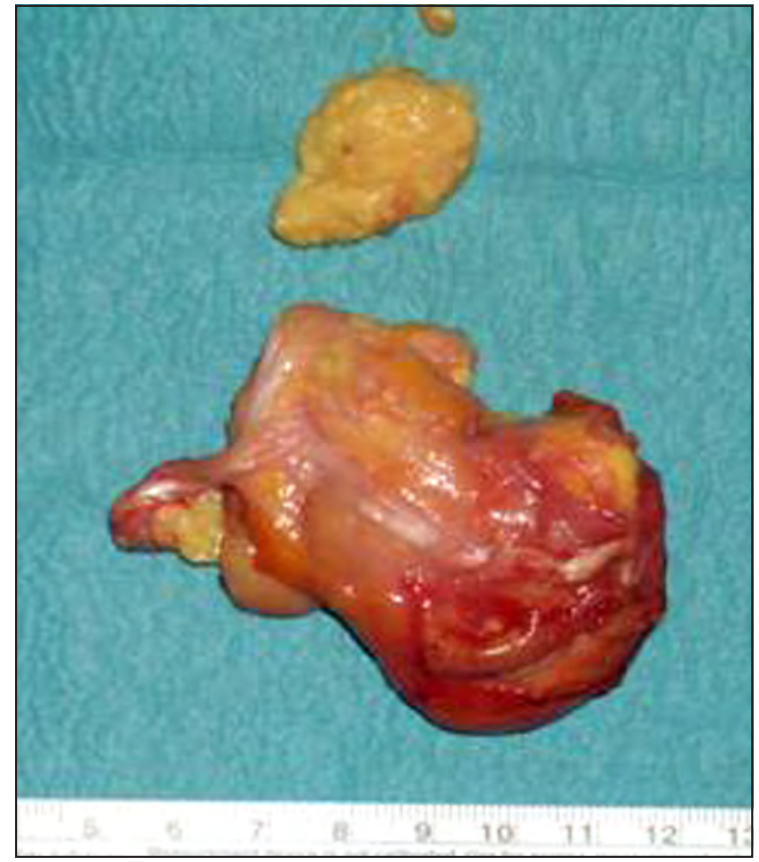

Figura 4: Pieza extirpada; sobre ella, parte de su contenido.

El anatomopatólogo, a quien se le envió la pieza ya abierta en quirófano para explorar el interior de la cavidad, informó de «Quiste bien delimitado de $6 \times 3,5 \times 2 \mathrm{~cm}$, de delgada pared elástica y lisa, de 0,1-0,2 cm de espesor uniforme, llena de material blando, grumoso y amari1lo. La descripción microscópica de la lesión extirpada es de carácter inflamatorio y no tumoral. La pieza forma un gran espacio seudoquístico lleno de material necrótico y delimitado por una delgada banda de tejido fibroso y tejidos blandos inflamatorios que podría corresponder a la pared de una bursa inflamada. La inflamación es crónica, formada por linfocitos y granulomas no tuberculosos ni sarcoideos, sino por histiocitos que se disponen en empalizada en torno a una zona central con necrosis y degeneración colágena en la que no se identifica mucina. Este mismo material es el que forma la mayor parte de la tumoración y llena el gran espacio descrito. Histológicamente, los granulomas que forman la lesión son similares a los que se observan en los nódulos reumatoides o en el granuloma anular. No se observa proliferación neoplásica ni cambios histológicos de malignidad» (sic).
La figura 4 muestra la pieza extirpada y parte de su contenido.

\section{DISCUSIÓN}

Aproximadamente existen unas 150 bolsas serosas en el cuerpo, situadas casi siempre sobre prominencias óseas con la función de facilitar el deslizamiento de los tendones. Por razones mecánicas algunas bursitis son muy frecuentes (subacromial, olecraneana, etc.) y otras sumamente raras.

La bursa bicipitorradial es pequeña y está situada entre la cara anterior de la tuberosidad bicipital del radio y el tendón del biceps brachii. En la AR la afectación extraarticular en el codo suele afectar a la bursa olecraneana, pero es muy infrecuente en la bicipitorradial.

La etiopatogenia de las bursitis y nódulos reumatoides es desconocida. Los nódulos se desarrollan casi siempre en pacientes con artritis reumatoide y están presentes al menos en el $20-25 \%$ de los afectos por esta enfermedad ${ }^{4,5}$. Suelen situarse en las proximidades de las articulaciones y su tamaño oscila entre 1 y $5 \mathrm{~cm}$ de diámetro ${ }^{4}$.

El diagnóstico diferencial de las bursitis profundas y de los nódulos reumatoides debe hacerse con tumoraciones subcutáneas de partes blandas, especialmente con lesiones nodulares de una paniculitis lobulillar ${ }^{4}$ y lipomas arborescentes de las bursas 5 .

Dentro de las complicaciones, tanto de las bursitis como de los nódulos reumatoides, están la infección, ulceración, gangrena y fistulización ${ }^{4}$.

Con respecto al tratamiento, las bursitis suelen requerir la realización de punciones evacuadoras, infiltración con corticoides o exéresis quirúrgica, mientras que los nódulos reumatoides habitualmente son asintomáticos y no requieren tratamiento ${ }^{4}$. Sólo precisan intervención quirúrgica aquéllos que se ulceran, infectan o limitan la movilidad articular ${ }^{6}$, o bien cuando por su tamaño o localización causan complicaciones como compresión vasculonerviosa o destrucción de los tejidos limítrofes ${ }^{7}$. 


\section{BIBLIOGRAFÍA}

1. Rotés Querol J. Manifestaciones extraarticulares de la artritis reumatoide. En: Reumatología Clínica, tomo 2. BarceIona: Edit. Espaxs S.A., 1983: 84-5.

2. González T, García-Montelongo R. Las conectivopatías en Medicina General. Nuevas perspectivas. Barcelona: Edit. Syntex Latino, 1989: 120-6.

3. Moleres Ferrandis R. Postulados Reumatológicos. Artritis Reu- matoide. Barcelona: Edit. CibaGeigy S.A., 1977: 98-103.

4. Requena L. Nódulo reumatoide. En: Herrera Ceballos E, Moreno Carazo A, Requena Caballero L, Rodríguez Peralta JL (Eds.). Dermatología: Correlación clínico-patológica. Barcelona: Área Científica Menarini, 2007: 436-8.

5. Mayayo-Sinués E, Soriano Guillén AP, Azúa Romeo J, Canales Cortés V. Lipoma arborescente de la bursa bicipital. Reumatol Clin, 2009; 5: 128-30.

6. Moreno-Sánchez M E, QuijanoGomero E, Cortez-Franco F, Rengifo-Pinedo L, CarayhuaPérez D. Nódulos auriculares ulcerados simétricos. Dermatología Peruana, 2007; 17: 123-31.

7. Irisarri C, Capomasi M. Tumores benignos de las partes blandas. En Tumores de la mano. Madrid: Editorial Médica Panamericana, 2009: 19-28. 